\title{
sciendo

\section{The Significance of Building Design for the Climate}

\author{
Aiman ALBATAYNEH ${ }^{1 *}$, Dariusz ALTERMAN², Adrian PAGE ${ }^{3}$, Behdad MOGHTADERI ${ }^{4}$ \\ ${ }^{1}$ Energy Engineering Department, German Jordanian University, Amman, Jordan \\ ${ }^{2-4}$ Priority Research Centre for Frontier Energy Technologies and Utilisation, \\ The University of Newcastle, NSW, Australia
}

\begin{abstract}
Building design is important for saving energy and reducing GHG emissions by applying passive solar heating and cooling design principles and using the right materials and appropriate design tools. This will make the home healthier and more comfortable. The design of energy efficient and sustainable buildings is critical for the future. A key aspect of any design is the realistic and accurate prediction of the performance of the building under a wide range of weather conditions. This paper examines the effect of different climate zones in Australia (which are comparable to the world's major climates) on the thermal performance of a complete building and recommended design techniques to suit each climate zone to enhance the overall thermal performance. To examine the effect of the location (different climates) on the overall thermal performance and how a good design in one location may not be suitable at another location, AccuRate will be used to assess the thermal performance for the exact module in different climates zones to allow a fair comparison to find the appropriate design for the climate where the building is located. Also, in this research, each climate zone design requirements and techniques were addressed for various climate variables (including: solar radiation, rainfall, wind speed and direction and humidity) to design sustainable building which save great amount of energy while sustaining occupants thermal comfort.
\end{abstract}

Keywords - Design for the climate; sustainable buildings; thermal performance

\section{INTRODUCTION}

As a result of the rapid economic and industrial growth in the last several decades, energy-related issues are becoming more and more important because of the possible energy shortage in the future [1]. That is in addition to the strongly related environmental and metrological problems related to energy consumption patterns worldwide. Nowadays, greater attention is being given to energy conservation by countries and research institutes, or even at an individual level. This attention is due to increased awareness regarding the importance of energy conservation and efficiency. Scientists across the world are working on energy management and control in order to develop strategies that would result in an overall reduction of energy consumption and high-quality and environmentally friendly energy usage.

Various studies are being conducted on energy consumption in residential buildings. These studies range from applying the proper methodologies to handle the problems, to conducting a detailed analysis of a certain building or technical study in the HVAC system. Further investigation is required in order to provide the suitable scientific foundation that can help decision makers and the general public to shift towards efficient energy consumption in the domestic sector.

One of the main sectors for energy consumption is the domestic or residential building sector. Thus, a lot of work is being done in this field to reduce the amount of energy consumed and

\footnotetext{
* Corresponding author.

E-mail address: aiman.albatayneh@gju.edu.jo 
improve quality of life with efficient energy consumption. The research conducted in this area has various aspects; one of these aspects is the improvement and development of methodologies and strategies. Advanced research on the methodologies that can be used in such studies has been conducted in order to provide the proper foundations in the field.

Several studies tried to review and compare the methodologies used in certain concepts such as modelling building energy systems, treatment of energy flow in buildings, and data collection [2], [3]. A process called Energy Operations Management (EOM) can be implemented to reduce energy consumption and costs by investing in the energy efficiency techniques [4]. Others went further and worked on the proper methodology to consider the effect of the behaviour of the building's occupants on the consumption of energy [5]. Many other studies elaborate more about the methodologies and approaches that can be implemented in analysing the energy consumption in buildings.

To meet the sustainability goals for the building sector, it is essential to develop new building concepts, technologies and materials that can further enhance the energy efficiency of buildings, while at the same time improving the indoor environmental comfort of the building's occupants [6]. This is one of the major aspects that have been considered to improve energy consumption in the domestic sector. For example, the outside building surface characteristics such as the colour and reflective coating [7] and their effect on the thermal performance of buildings has been conducted in different environments.

On the other hand, the simulation and modelling of buildings to study the energy consumption is also gaining the attention of research groups worldwide. Usually, simulations are conducted to predict the energy needs for a certain building configuration, additionally, it is conducted to establish a comparison with the real situation [8]. The importance of the simulation in the decision-making process and early incorporation of simulation software, faces several challenges, e.g.; excessive modelling time, inconsistent requirements and large design variability.

Various codes and software have been developed (and commercially available) for this purpose, such as; StruBim by CYPE, IDA Indoor Climate and Energy by EQUA Simulation AB, DesignBuilder by DesignBuilder USA, eQUEST by James J. Hirsch \& Associates (JJH), and many other codes. Applications of the methodologies and simulations are being conducted regularly, especially when a new process or code is developed [9].

Others assessed the building performance simulation results to the actual measurements for predicting building energy performance [9]. In the same scope of research, Tronchin and Fabbri analysed and compared three different numerical codes/models for the energy performance of the building's software calculations against real energy consumptions to identify possible gaps in the simulation field in general. Thus, the database of simulation performance is rapidly increasing. Such a database is important because when choosing which simulation tool to use in a project, the user must consider the tool's accuracy and reliability, and this can be done by providing the code or simulation results compared with the actual building measurements [10].

Researchers reviewed how Data Science has been applied to address the most difficult problems faced by practitioners in the buildings energy sector [6]. A study on energy-efficient design strategies for two climatic zones in Turkey evaluated the thermal performance of two buildings (constructed according to certain regional Turkish standards), this highlighted that there were considerations in the implemented standards, for example, the study showed that the standards have made a significant mistake by neglecting the heat storage capacity in hot-dry climate regions. In addition, a study concluded that the response to the climate of the region with two climate zones should not be considered as one zone [11]. The relation between the climate 
zoning and energy performance in buildings, which were investigated during hot summer periods and their impact on a building's thermal-energy behaviour, show it is extremely important in an urban area to use a statistical analysis of the microclimate variation during monitored hot periods. This work distinguishes between the timely variation of the climate and not just the areal/regional zoning [12].

Space heating and cooling from different types of fuel consuming a significant amount of energy in Australia can be reduced by appropriate climate passive design. There are different climate zones in Australia similar to the major climates around the world as shown in Fig. 1 which represents the major climate zones in Australia.

The main climate zones in Australia are:

- Warm humid summer, mild winter, the main features of this zone are high diurnal (day/night) temperature ranges and four distinct seasons where autumn and spring are ideal for the human comfort range, while winter has low humidity which is outside the human comfort range and hot to very hot summers with moderate humidity which exceed the human comfort range;

- High humid summer, warm winter, this climate zone is located at the north of the Tropic of Capricorn, where the sun is in the southern sky during some of the summer. The summer (wet season) is hot, humid and usually experiences high-levels of rain. The winter (dry season) is warm, dry and sunny;

- Hot dry summer, warm winter, this zone's typical characteristics are: hot summers, winter days may be warm and cool winter nights, big temperature differences between day and night. High sun glares during summer days;

- Hot dry summer, cool winter zone in Australia, which has: hot summers with high sun glare; winter can be cold, dry air; big temperature differences between day and night;

- Mild to warm summer, cold winter (Cool Temperate Zone) which is: mild to warm summers and cold winters and in the higher parts of the Snowy Mountains, snow can fall at any time of the year. In Tasmania, summer snow has been known to fall at elevations as low as $300 \mathrm{~m}$.

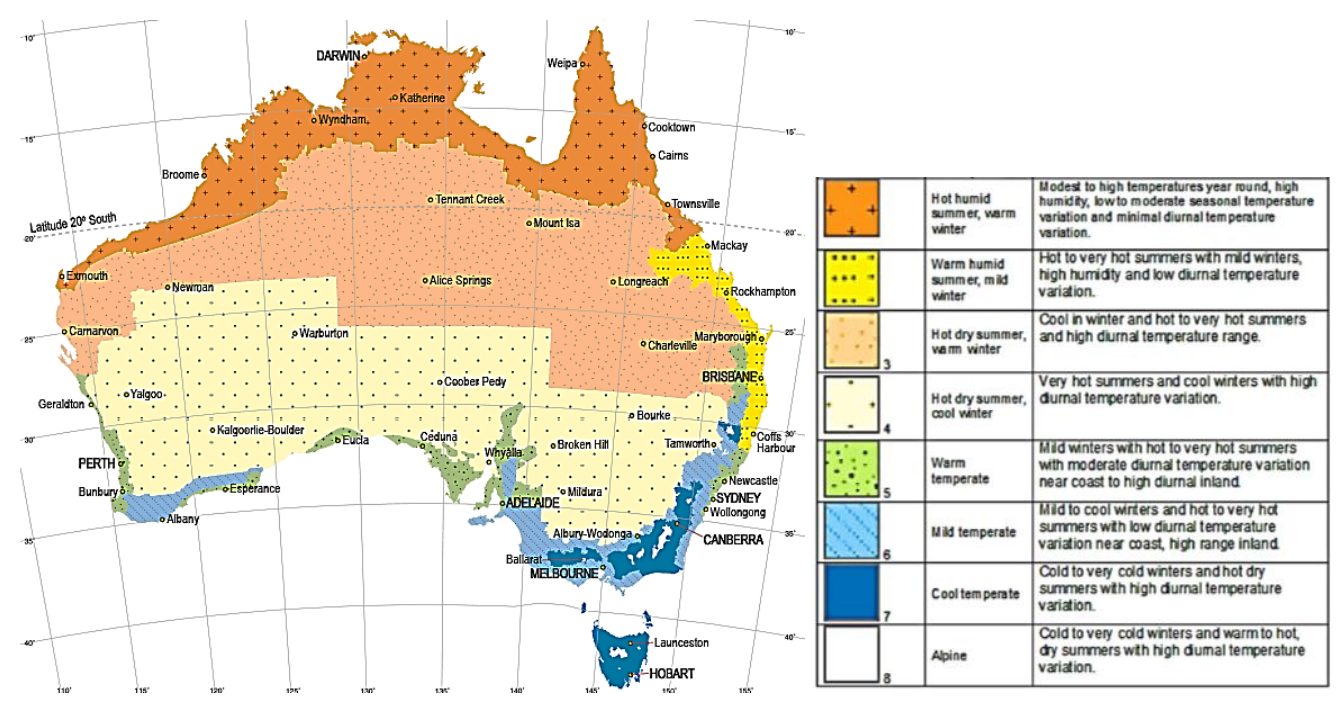

Fig. 1. Major climate zone in Australia with their features [13]. 
Improving the energy efficiency of the buildings could be achieved by general measures to avoid heat loss in all climates. For walls and roofs, airtight construction is required, which can save up to $25 \%$ of heating costs [14], bulk insulation, and passive heating using solar radiation which can be absorbed by higher thermal mass walls in the winter months. Appropriately sized windows, oriented and shaded windows, and double-glazed for better insulation.

There are common procedures to avoid heat gain for all climates. For windows; using small windows with proper orientation, shading and low-E glass for lower radiation absorption. For walls and roofs, it is vital to use lightweight construction for rapid cooling, reflective and bulk insulation, light colours to reflect radiation, airtight construction especially when air-conditioning is in use, shading for external walls (i.e. trees), high thermal mass (where diurnal temperature swings are high), controlled ventilation to dissipate heat from the building.

A technical manual has been developed by the Department of Climate Change and Energy Efficiency in Australia (DCCEE), to show how to design and build more comfortable homes that have less impact on the environment, are more economical to run, healthier to live in and are adaptable to the changing climate. This manual provides the general rules which apply in the different climate zones in Australia (in this report most of the techniques used to improve the thermal performance for each climate zone were concluded from this manual) [14].

The results for base temperatures of $21^{\circ} \mathrm{C}$ for cooling (21CDD) and $15^{\circ} \mathrm{C}$ for heating (15HDD) are presented in Fig. 2. The red zones represent areas of Australia where cooling is needed more than twice as much as heating. Light green and blue zones represent areas where heating is predominantly required.

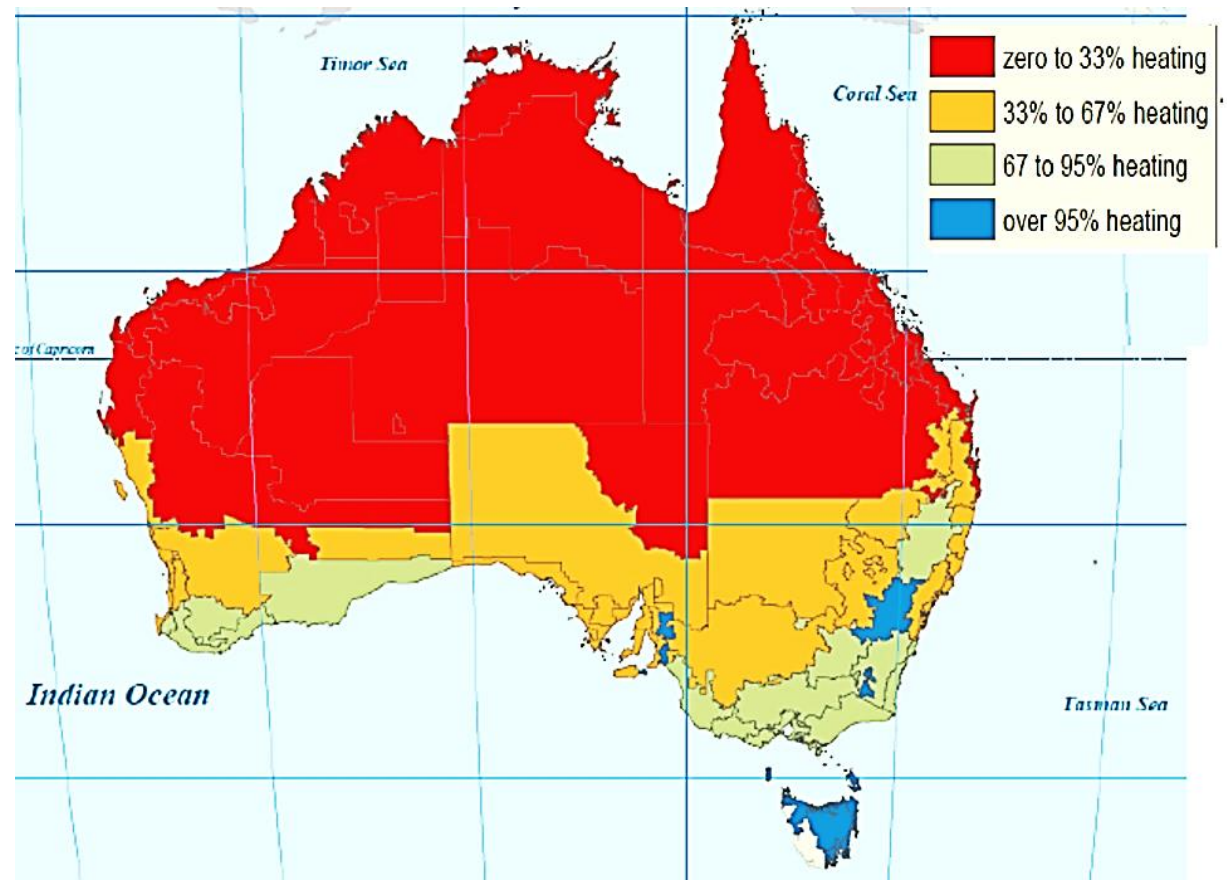

Fig. 2. Australian heating and cooling requirements of $21^{\circ} \mathrm{C}$ for cooling (21CDD) and $15{ }^{\circ} \mathrm{C}$ for heating (15HDD) [15]. 
In the hot and dry climate of India, common practice is to build with high thermal mass structures which provide better thermal comfort environments for the occupants rather than the lower thermal mass buildings where there is not enough night ventilation, otherwise the high thermal mass houses can be uncomfortable [16].

In high humid climates, high mass buildings are not preferred due to their small diurnal variation. Low thermal mass constructions are recommended as they respond quickly to cool breezes. A study conducted in Thailand on the economic performance of high and low thermal mass walls concluded that higher thermal mass walls delay the rise in internal surface temperatures during the daytime. On the other hand, it raises the internal temperature during the night. The study also found that higher thermal mass walls are not economical in tropical regions such as Malaysia, as low thermal mass buildings are recommended to sustain the occupant's thermal comfort [17].

A new study to investigate the effect of thermal mass in cold climates with active heating and hot climates with active cooling were carried out. The study agreed with current literature that high thermal mass buildings are likely to be beneficial in a hot climate with high diurnal variation; however, in cold climates the high thermal mass buildings can increase the energy consumption compared with lower thermal mass constructions of identical floor area, U-value and air-tightness [18].

\section{Methodology}

\subsection{Full Scale Test Module (InsCB)}

In the last decade an intensive ongoing research program by the Priority Research Centre for Energy at the University of Newcastle, Australia has involved the construction and monitoring of four full scale housing modules under a variety of weather conditions (Cavity Brick (CB), Insulated Cavity Brick (InsCB), Insulated Brick Veneer (InsBV) and Insulated Reverse Brick Veneer (InsRBV)). Each module was selected to characterise typical forms of local construction in Australia and are located at the University of Newcastle (UON), Callaghan campus (151.7 longitude and -32.89 latitude) [18].

This paper will examine the Insulated Cavity Brick module (InsCB) as a case study to examine the effect of the location with different climates on the overall building thermal performance. The module has a square floor plan of $6 \mathrm{~m} \cdot 6 \mathrm{~m}$ and the full module description in Fig. 3 [18]. 


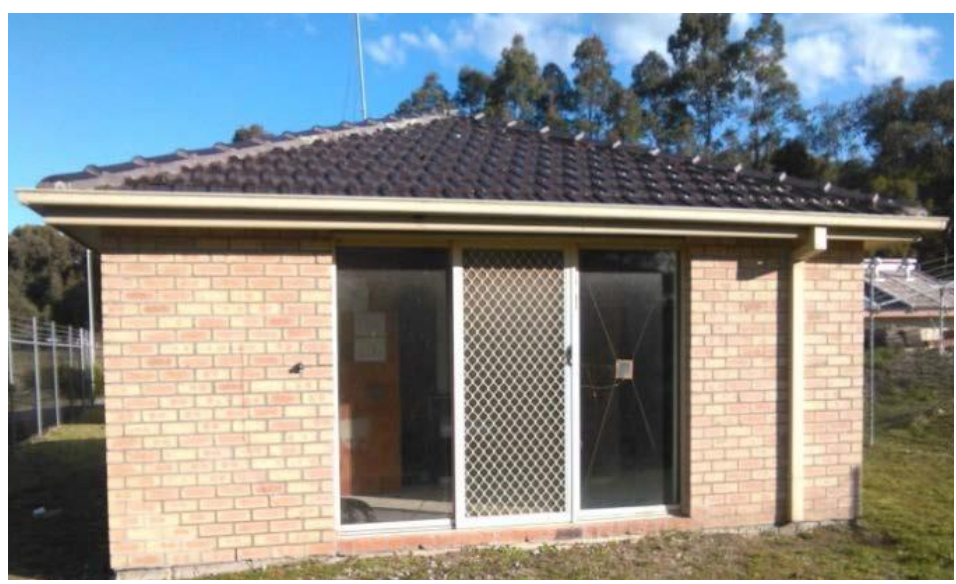

(a)

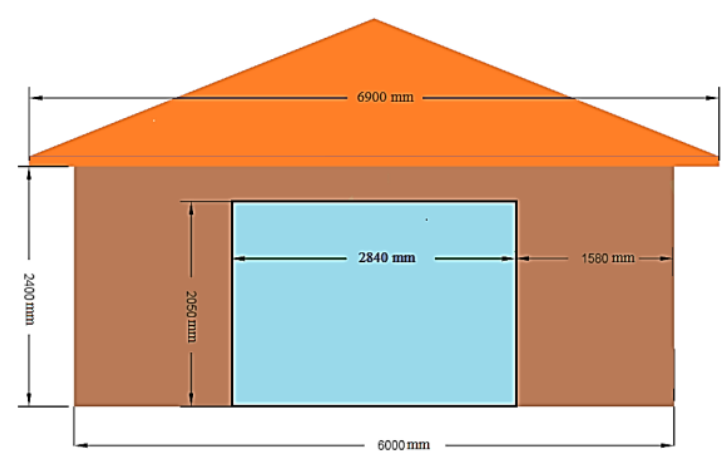

(b)

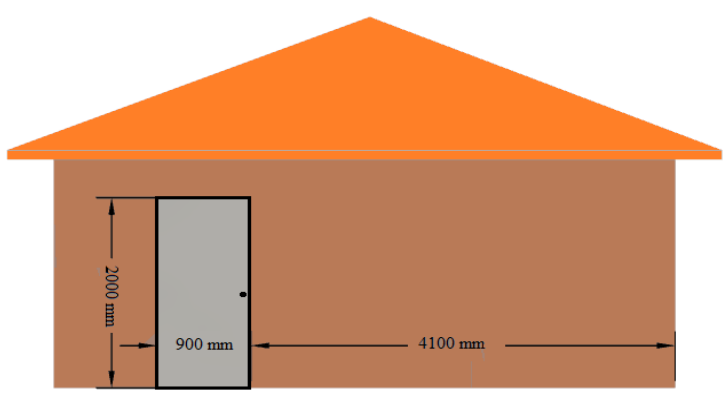

(d)

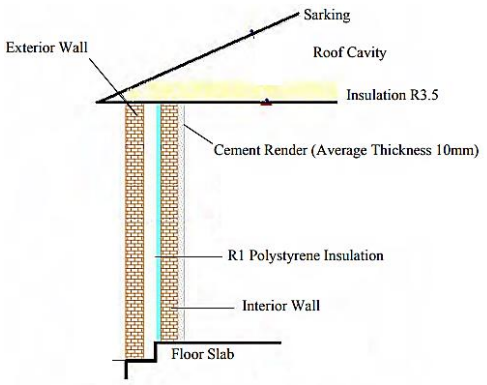

(c)

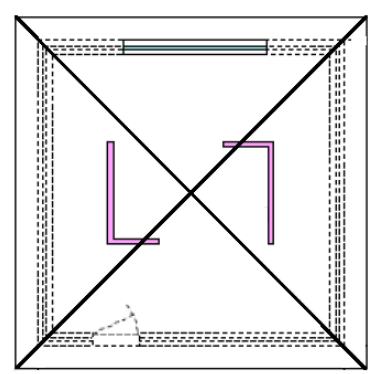

(e)

Fig. 3. Real module photos, including north, south and top view plans for all modules: (a) the Northern face; (b) North plan for all modules; (c) walling system; (d) South face; (e) top view plan [19].

The details of the wall systems used are summarised in Table 1. 
TABle 1. InsCB Module ElEments AND Material Configurations [19], [20]

\begin{tabular}{lll}
\hline Module element & $\begin{array}{l}\mathrm{U}-\mathrm{value}, \\
\mathrm{W} / \mathrm{m}^{2} \cdot \mathrm{K}\end{array}$ & Material configurations \\
\hline $\begin{array}{l}\text { External walls (Insulated } \\
\text { Cavity Brick) }\end{array}$ & 0.617 & $\begin{array}{l}\text { Two } 110 \mathrm{~mm} \text { brickwork skins with } 50 \mathrm{~mm} \text { cavity with R1 polystyrene } \\
\text { insulation and } 10 \mathrm{~mm} \text { render covered the internal walls } \\
\text { Roof (Clay) }\end{array}$ \\
$\begin{array}{ll}\text { Clay tiles over a layer of foil sarking } \\
\text { Door }\end{array}$ & 0.588 & $\begin{array}{l}2040 \cdot 820 \mathrm{~mm} \text { standard solid timber door insulated by } 75 \mathrm{~mm} \text { thick } \\
\text { layer of polystyrene foam }\end{array}$ \\
Window & 5.763 & $\begin{array}{l}2050 \cdot 2840 \mathrm{~mm} \text { clear glass set in a light coloured aluminum frame } \\
10 \mathrm{~mm} \text { plasterboard and R3.5 glass-wool batts between rafters }\end{array}$ \\
Ceiling & 0.286 & Concrete slab \\
Slab & 0.862 &
\end{tabular}

Insulated Cavity brick modules consist of $110 \mathrm{~mm}$ thick brickwork skins with $50 \mathrm{~mm}$ cavity (R1 polystyrene insulation fixed to cavity side of interior brick skin) and the $110 \mathrm{~mm}$ internal wall covered by $10 \mathrm{~mm}$ internal render.

The overall wall U-value of $0.617 \mathrm{~W} / \mathrm{m}^{2} \cdot \mathrm{K}$ represents the reciprocal of the R-values and are usually used to express the overall heat transfer coefficient for the wall system, including inside and outside air film resistances. The U-values for surface to-surface have been included only to highlight the contribution of air film resistances. Under steady-state conditions, the U-value is a direct measure of the rate of heat transfer (in Watts) through a $1 \mathrm{~m}^{2}$ area of the building element when it is subjected to a temperature difference of $1{ }^{\circ} \mathrm{C}$.

A major opening (window) was installed in the northern wall of each module, where a typical living room to floor area ratio nearly $20 \%$ (the winter sun enters the module during winter through the northern window in the southern hemisphere). Each module includes two internal L-shape walls $2 \mathrm{~m} \cdot 1 \mathrm{~m}$ with a height of $2 \mathrm{~m}$ and $110 \mathrm{~mm}$ thick. The ceilings were heavily insulated with R3.5 glass wool batts to minimise/eliminate heat loss through the ceiling. The temperature inside each module was determined only by the influence of the external weather conditions (free-floating state) and no heating or cooling was applied [21].

\subsection{AccuRate}

Commonwealth Scientific and Industrial Research Organization (CSIRO) have developed a software tool for house energy modelling called AccuRate in partnership with the Australian Government Department of Climate Change. AccuRate is currently the standard software for house energy rating in Australia for compliance with the Australian National Building Code. The program has been evaluated against the International Energy Agency BESTEST, which found that it compared well against their eight reference programs from the US and Europe.

AccuRate enables house designers to calculate temperatures, heating and cooling energy requirements on an hourly basis, and assess a house's energy efficiency in any one of 69 different climatic zones in Australia. The model includes a wide range of factors that impact a house's energy efficiency; such as "natural ventilation, insulation, air leakage, thermal mass, roof spaces, sub-floor spaces, skylights, horizontal reflective air gaps, windows, and external shading structures such as neighbouring buildings, trees and fences. It also includes extra modules that allow designers to investigate other sustainability parameters outside the energy efficiency rating, like lighting, space heating and cooling, hot water, water usage, and embodied carbon dioxide" [22]. 
AccuRate Sustainability (V2.3.3.13 SP1) is assessment software that gives a star rating to residential buildings in Australia. This tool calculated annual cooling and heating energy required to sustain the occupant's thermal comfort. The results of the assessment process for any building is specified as a star rating between 0 and 10, the higher the stars (bands), the better the thermal performance of the building [21].

AccuRate star ratings are set for each specific climate zone to allow fair comparison of the buildings across climates despite extreme regional variability in weather conditions across Australia. All conditioned spaces must be maintained within a certain range of thermal comfort. The heating and cooling energy requirements are calculated hourly over a period of one year. Shown in Table 2 is an example for the Newcastle area (Zone 15), where the lower energy requirements, the higher the stars [23]. Cooling thermostat settings in AccuRate assumed that the thermostat trigger point ranges from $22.5{ }^{\circ} \mathrm{C}$ for alpine zones to $28.5{ }^{\circ} \mathrm{C}$ in very hot zones. For the heating thermostat settings, it ranges from $20^{\circ} \mathrm{C}$ for living spaces and $18{ }^{\circ} \mathrm{C}$ for sleeping spaces [24].

TABle 2. ANNUAl ENERgy REQUiREMENTS (MJ/M²·ANNUM) FOR EACH STAR RATING [25]

\begin{tabular}{llllllllll}
\hline 1 Stars & 2 Stars & 3 Stars & 4 Stars & 5 Stars & 6 Stars & 7 Stars & 8 Stars & 9 Stars & 10 Stars \\
\hline 349 & 232 & 159 & 114 & 86 & 67 & 50 & 34 & 19 & 6 \\
\hline
\end{tabular}

\section{RESUlts AND Discussions}

From previous studies, the Insulated Cavity Brick module has the best thermal performance in the Newcastle area in Australia compared with the rest of the modules (Cavity Brick, Insulated Brick Veneer and Insulated Reverse Brick Veneer) [26], [27]. Using AccuRate to assess the thermal performance of the Insulated Cavity Brick module in different climate zones were shown in Table 3 and Fig. 4.

TABle 3. STAR RATING AND ANNUAl ENERGy REQUiREMENTS FOR INSCB MODULE IN DIFFERENT LOCATIONS IN AUSTRALIA

\begin{tabular}{lll}
\hline Location & Star rating & $\mathrm{kWh} / \mathrm{m}^{2} \cdot$ annum \\
\hline Sydney, NSW & 9.2 & 2.5 \\
Melbourne, Vic & 6.5 & 27.2 \\
\hline Newcastle, NSW & 8.9 & 3.9 \\
Adelaide, SA & 7.9 & 16.9 \\
Alice Spring, NT & 7.5 & 22.2 \\
Brisbane, QLD & 9.3 & 3.3 \\
Hobart, TAS & 5.9 & 45.8 \\
Perth, WA & 9.2 & 2.8 \\
Darwin, NT & 6.7 & 84.5 \\
\hline
\end{tabular}

Note: Newcastle is located $170 \mathrm{~km}$ north of Sydney with an almost similar climate. 


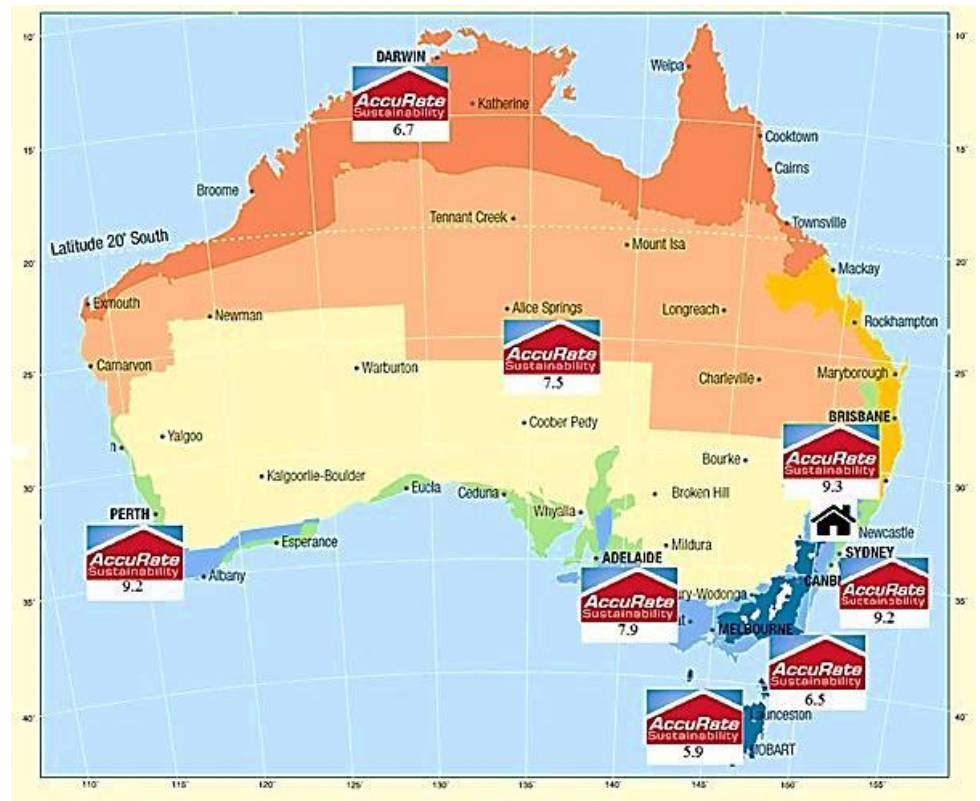

Fig. 4. AccuRate rating for different locations/climate zones in Australia [14].

Designing for the climate is important because each location requires different design techniques. For example, if the location of an InsCB module is changed from Newcastle to Perth the star rating will increase from 8.9 to 9.2 and if it is changed to Darwin it drops to 6.7.

Colder climates such Melbourne and Hobart will result in a greater need for heating energy because of the large un-insulated window. On the other hand, in hot climates such as Darwin this will result in lower thermal performance because of the increase in cooling energy required caused by the high thermal mass of the walls and the radiation entering the module through the northern facing window (Southern Hemisphere).

\subsection{Design Techniques for Sustainable Design in Each Climate Zone}

The InsCB module design and materials were suitable for temperate zones that typically experience mild to warm summers and cool winters (Sydney, Newcastle, and Perth). In this climate the need for winter heating is greater than the need for summer cooling. During the summer months, the temperature at night is lower than $20^{\circ} \mathrm{C}$ on average, so allowing the cool night air to ventilate the building cools the air and dissipates the thermal mass heat from the walls making the building cool during the day.

The main design requirements in a temperate climate are: glass facing north (Southern Hemisphere), with shading designed to absorb the sun's heat during winter and block it in the summer months, internal thermal mass to absorb the heat during the winter days and reradiate it inside the building during the night, air-tight construction to minimise heat losses, a light coloured roof is essential in the summer months to reflect most of the sun's radiation heat back into the atmosphere - this will not affect winter solar heat gain as the winter sun is angled lower in the sky, shining more on the walls than on the roof, so the reduction of winter solar heating through the light coloured roof is minimised. 
Design the building to facilitate cross ventilation by opening windows at night, and keeping them closed during the hot days, and shading the east and west walls in summer (i.e. trees) can cool the house. Ceiling insulation is needed for Sydney and Newcastle, but more insulation is required for Melbourne and Adelaide.

InsCB is suitable for temperate climates and does not suit cool temperate climates - mild to warm summer, cold winter (i.e. Melbourne, Tasmania). In a cool temperate climate, the techniques as per the temperate zone, and bigger north facing and east facing windows with double glazing (with exterior shading to eliminate the summer sun) to facilitate the penetration of the morning sunlight during the cooler months and more airtight construction with heavier bulk insulation to keep the heat inside the building is needed.

A hot humid climate is located in the northern part of Australia (i.e. Darwin). The InsCB design was not suitable for these kinds of climates which need a minimum sized window on the east and west walls to decrease heat gain throughout the year and the building heat gain can be reduced by positioning the long axis of the house east-west for cross ventilation also ventilating the roof space to reduce accumulated heat. Lighter house construction materials (timber, fibrous cement) will store less heat and due to its low thermal mass will cool faster at night since the day to night temperature fluctuation is smaller and as the average daily outdoor temperature is too high for comfort, materials with high thermal mass, such as bricks and concrete will not work specifically in this climate. Light colours for walls and roof, to reflect the sun radiations and dissipate heat quickly at night. Shading the walls and windows with suitable shutters, verandas and eaves will protect the building from the summer sun.

For high humidity climates, air movement is vital to help perspiration to evaporate. Main design requirements for a hot humid climate are that windows facing each other to facilitate cross ventilation with a long, narrow floor-plan to maximise ventilation in bedrooms, also open-plan living areas with a high roof, to increase air circulation and minimise roof radiant heat to the residents. If there is no air-conditioning, reflective foil insulation performs better than bulk insulation because it stops the building from cooling down during the night. Otherwise it requires bulk insulation and double-glazed windows.

Hot dry zone with warm winter (i.e. Alice Springs), because of the intense solar radiation, we have to apply: light colored external surfaces to reflect the sun, reflective foil insulation in the walls and roof. If air-conditioned, the building requires bulk insulation. Also, small well shaded north facing windows will improve the thermal performance. The hotter the summer, the smaller the windows, but smaller windows will reduce night ventilation. No windows or very small windows on the eastern or western side of the house. Earth sheltered, and underground housing can be used because it has a large thermal mass to maintain the building's thermal comfort.

Because of the large day to night temperature variation, thermal mass in the living areas to cool the building during the day and low thermal mass for the bedrooms to cool rapidly at night using cross ventilation. Roof mounted exhaust fans for night cooling will improve the thermal comfort.

Hot dry with cold winter, similar in some features to a hot dry climate, but with mild winters because of the large difference between summer and winter temperatures, shading is important to keep out the summer sun and to allow the winter sun to enter (trees may be used for shading around the house) and because the winter is cold. To allow solar passive heating in winter, windows (north facing) should be larger than those in a hot dry climate with a warm winter. Bulk insulation is required to reduce heat loss through the walls and ceilings. Moderate insulation for bedrooms with lighter construction (low thermal mass) will help to cool fast at night, in addition to air tight construction to reduce heat loss. 


\subsection{Recommendations for Different Climate Zones}

Table 4 summarises the recommendations to achieve higher star rating for InsCB Module in different climate zones.

\section{TABLE 4. RECOMMENDATIONS TO ACHIEVE HIGHER STAR RATING FOR INSCB MODULE IN DIFFERENT CLIMATE ZONES}

\begin{tabular}{|c|c|}
\hline Climate zone & Recommendations \\
\hline $\begin{array}{l}\text { Warm to mild temperate } \\
\text { zone }\end{array}$ & $\begin{array}{l}\text { Higher thermal mass especially to the internal walls facing north windows to absorb } \\
\text { the heat during the winter day and reradiate it inside the building during the night } \\
\text { Facilitate cross ventilation during cool summer night } \\
\text { Eliminate air drafting through leaky walls and windows } \\
\text { Light coloured roof and darker walls especially the northern walls to absorb winter sun } \\
\text { Shade the east and west walls in summer (i.e. trees) } \\
\text { Bulk Insulation is needed and double glazed windows }\end{array}$ \\
\hline $\begin{array}{l}\text { Cool temperate climate and } \\
\text { Alpine }\end{array}$ & $\begin{array}{l}\text { As per mild temperate zone in addition to: } \\
\text { - Bigger north facing windows } \\
\text { - Insulated windows } \\
\text { - More airtight construction } \\
\text { - Heavier bulk insulation }\end{array}$ \\
\hline Hot humid climate & $\begin{array}{l}\text { Minimise windows size to a certain size without affecting the cross ventilation } \\
\text { Positioning the long axis of the house facing main wind direction for cross ventilation } \\
\text { Ventilating the roof space to reduce accumulated heat } \\
\text { Low thermal mass construction (timber, fibrous cement). Materials with high thermal } \\
\text { mass, such as bricks and concrete will not work specifically in this climate } \\
\text { Light colours for walls and roof } \\
\text { Shading the walls and windows with suitable shutters, verandas and eaves could work } \\
\text { to protect from the summer sun }\end{array}$ \\
\hline Warm humid climate & $\begin{array}{l}\text { On top of the recommendations in hot humid climates } \\
\text { Windows better to face each other to facilitate cross ventilation } \\
\text { Long, narrow floor-plan to maximise ventilation in bedrooms } \\
\text { Open plan living areas with high roof, to increase air circulation and minimise roof } \\
\text { radiant heat to the residents }\end{array}$ \\
\hline $\begin{array}{l}\text { Hot dry zone with warm } \\
\text { winter }\end{array}$ & $\begin{array}{l}\text { Light coloured external surfaces to reflect the sun } \\
\text { Reflective foil insulation in the walls and roof } \\
\text { Small north facing windows } \\
\text { Well shaded } \\
\text { Earth sheltered and underground housing can be used because it has large thermal } \\
\text { mass to maintain the building's thermal comfort } \\
\text { Higher thermal mass in the living areas to cool the building during the day and low } \\
\text { thermal mass for the bedrooms to cool rapidly at night using cross ventilation } \\
\text { Roof mounted exhaust fans for night cooling }\end{array}$ \\
\hline $\begin{array}{l}\text { Hot dry summer with cold } \\
\text { winter }\end{array}$ & $\begin{array}{l}\text { On top of the recommendations to the hot dry climates } \\
\text { Shading is important to keep out the summer sun and to allow the winter sun to enter } \\
\text { Trees may be used for shading around the house } \\
\text { Larger north facing windows than in a hot dry climate with a warm winter } \\
\text { Bulk insulation } \\
\text { Air tight construction to reduce heat loss }\end{array}$ \\
\hline
\end{tabular}




\section{Conclusions}

Designing economical and energy efficient buildings that react to the climatic conditions found at the site, require studying and analysing the impact of the different climate zones. Choosing the right building components/materials suitable to each climate condition is essential for sustainable developments.

Insulated Cavity Brick module (InsCB) has the best thermal performance in the Newcastle area in Australia compared with the rest of the modules (Cavity Brick, Insulated Brick Veneer and Insulated Reverse Brick Veneer). Using AccuRate to assess the thermal performance of the Insulated Cavity Brick module in different climate zones showed that the best suitable design module for one area was not suitable for the other climates.

In general, to avoid heat loss in all climates these design techniques should be applied; airtight construction; bulk insulation; thermal mass for the walls and floor; passive heating using solar radiation in the winter months; appropriately sized, oriented and shaded windows; double-glazed for better insulation. General measures to avoid heat gain for all climates; small east and west windows; shading and low-e glass for lower radiations absorption; lightweight construction for rapid cooling; reflective insulation; light colours to reflect radiation; shading for external walls (i.e. trees) and high thermal mass (where diurnal temperature swings are high) with proper ventilation to dissipate heat from the building.

Final results showed that the InsCB module (which is the best thermal performing module among all the modules located on the site) is suitable for Sydney, Perth and Brisbane climates and not suitable for colder climates due to large un-insulated glazing areas (north window), and is also inappropriate for the hot and humid climates because of the higher thermal mass of the walls which required cooling energy to overcome the heat stored inside the thick walls.

Each climatic zone requires different design techniques which need to be addressed accurately by understanding climate variables (including: solar radiation, rainfall, wind speed and direction and humidity) to design sustainable buildings. Designing for the climate is crucial for design sustainability, which if addressed accurately can save massive amounts of heating and cooling energy whilst sustaining occupants' thermal comfort.

\section{ACKNOWLEDGEMENTS}

This research project has been supported by the Australian Research Council (LP 120100064) and Think Brick Australia.

\section{REFERENCES}

[1] Yu R., Xu Y., Zhou T., Li J. Relation between rainfall duration and diurnal variation in the warm season precipitation over central eastern China. Geophysical research letters 2007:34(13). doi:10.1029/2007GL030315

[2] Harish V. S., Kumar A. A review on modeling and simulation of building energy systems. Renewable and Sustainable Energy Reviews 2016:56:1272-92. doi:10.1016/j.rser.2015.12.040

[3] Paudel S., Elmitri M., Couturier S., Nguyen P. H., Kamphuis R., Lacarriere B., Le Corre O. A relevant data selection method for energy consumption prediction of low energy building based on support vector machine. Energy and Buildings 2017:138:240-56. doi:10.1016/j.enbuild.2016.11.009

[4] Hoikka J. Managing the Energy Performance of a Large Building Stock. Master Thesis, Aalto University.

[5] Jia M., Srinivasan R. S., Raheem A. A. From occupancy to occupant behavior: An analytical survey of data acquisition technologies, modeling methodologies and simulation coupling mechanisms for building energy efficiency. Renewable and Sustainable Energy Reviews 2017:68:525-40. doi:10.1016/j.rser.2016.10.011 
[6] Molina-Solana M., Ros M., Ruiz M. D., Gomez-Romero J., Martin-Bautista M. J. Data science for building energy management: A review. Renewable and Sustainable Energy Reviews 2017:70:598-609. doi:10.1016/j.rser.2016.11.132

[7] Synnefa A., Santamouris M., Apostolakis K. On the development, optical properties and thermal performance of cool colored coatings for the urban environment. Solar Energy 2007:81(4):488-97. doi:10.1016/j.solener.2006.08.005

[8] Ostergard T., Jensen R. L., Maagaard S. E. Building simulations supporting decision making in early design A review. Renewable and Sustainable Energy Reviews 2016:61:187-201. doi:10.1016/j.rser.2016.03.045

[9] Yezioro A., Dong B., Leite F. An applied artificial intelligence approach towards assessing building performance simulation tools. Energy and Buildings 2008:40(4):612-20. doi:10.1016/i.enbuild.2007.04.014

[10] Tronchin L., Fabbri K. Energy performance building evaluation in Mediterranean countries: Comparison between software simulations and operating rating simulation. Energy and buildings 2008:40(7):1176-87. doi:10.1016/j.enbuild.2007.10.012

[11] Yilmaz Z. Evaluation of energy efficient design strategies for different climatic zones: Comparison of thermal performance of buildings in temperate-humid and hot-dry climate. Energy and Buildings 2007:39:306-316. doi:10.1016/j.enbuild.2006.08.004

[12] Pyrgou A., Castaldo V. L., Pisello A. L., Cotana F., Santamouris M. On the effect of summer heatwaves and urban overheating on building thermal-energy performance in central Italy. Sustainable Cities and Society 2017:28:187-200. doi:10.1016/j.scs.2016.09.012

[13] McGee C., Reardon C. Design for climate. Your Home: Australia's guide to environmentally sustainable homes. 5th edition: Department of Industry, Commonwealth of Australia.

[14] DCCEE. Your Home Technical Manual. Department of Climate Change and Energy Efficiency. Australia's guide to environmentally sustainable homes. 4th Edition, 2010.

[15] Peterson E. Climate zone mapping for air conditioners and heat pump devices. Energy Rating, Commonwealth of Australia (Department of Industry) 2014.

[16] Kumar S., Tewari P., Mathur S., Mathur J. Development of mathematical correlations for indoor temperature from field observations of the performance of high thermal mass buildings in India. Building and Environment 2017:122:324-42. doi:10.1016/j.buildenv.2017.06.030

[17] Mirrahimi S., Mohamed M. F., Haw L. C., Ibrahim N. L., Yusoff W. F., Aflaki A. The effect of building envelope on the thermal comfort and energy saving for high-rise buildings in hot-humid climate. Renewable and Sustainable Energy Reviews 2016:53:1508-19. doi:10.1016/j.rser.2015.09.055

[18] Reilly A., Kinnane O. The impact of thermal mass on building energy consumption. Applied Energy 2017:198:10821. doi:10.1016/j.apenergy.2017.04.024

[19] Albatayneh A., Alterman D., Page A., Moghtaderi B. The significance of time step size in simulating the thermal performance of buildings. Advances in Research 2015:5(6):1-12. doi:10.9734/AIR/2015/20223

[20] Page A., Moghtaderi B., Alterman D., Hands S. A study of the thermal performance of Australian housing. The University of Newcastle.

[21] Albatayneh A., Alterman D., Page A., Moghtaderi B. Assessment of the Thermal Performance of Complete Buildings Using Adaptive Thermal Comfort. Procedia-Social and Behavioral Sciences 2016:216:655-661. doi:10.1016/j.sbspro.2015.12.051

[22] Delsante A. Is the new generation of building energy rating software up to the task? A review of AccuRate. ABCB Conference "Building Australia's Future 2005", 11-15 September 2005, Gold Coast, Australia.

[23] NatHERS National Administrator. Nationwide house energy rating scheme (NatHERS) - Software accreditation protocol, 2012.

[24] Chen D. AccuRate and the Chenath Engine for Residential House Energy Rating, 2018.

[25] Albatayneh A., Alterman D., Page A., Moghtaderi B. The Significance of Temperature Based Approach Over the Energy Based Approaches in the Buildings Thermal Assessment. Environmental and Climate Technologies 2017:19:39-50. doi:10.1515/rtuect-2017-0004

[26] Albatayneh A., Alterman D., Page A., Moghtaderi B. Thermal Assessment of Buildings Based on Occupants Behavior and the Adaptive Thermal Comfort Approach. Energy Procedia 2017:115:265-271. doi:10.1016/j.egypro.2017.05.024

[27] Albatayneh A., Alterman D., Page A., Moghtaderi B. Discrepancies in Peak Temperature Times using Prolonged CFD Simulations of Housing Thermal Performance. Energy Procedia 2017:115:253-264. doi:10.1016/j.egypro.2017.05.023 

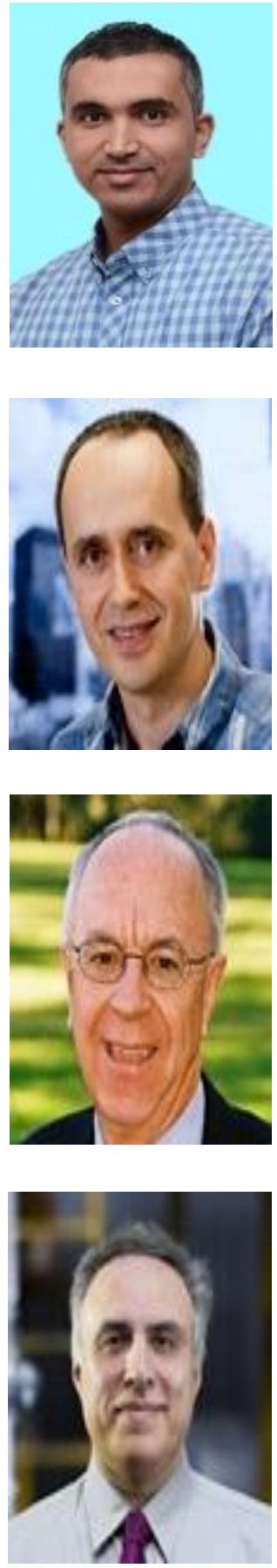

Dr. Aiman Albatayneh received the Ph.D. degree in engineering from the University of Newcastle, Australia (UON) in 2016 after completing B.Sc. in renewable energy engineering (honours) from the University of New South Wales (UNSW) in 2013.

Currently he is an Assistant Professor in the Energy Engineering Department, School of Natural Resources Engineering and Management, German Jordanian University, Amman, Jordan. His research interests include; thermal performance of buildings, sustainable buildings design and renewable energy technologies for sustainable developments.

He has been elected graduate of the Instate of Engineers Australia in the Mechanical, Electrical and Civil colleges.

Dr. Dariusz Alterman received the Ph.D. degree in engineering from at the prestigious Polish Academy of Sciences in 2005 after completing two Master degrees at Rzeszow University of Technology in Poland.

Currently he works as a Senior Research Fellow in the School of Civil Engineering at the University of Newcastle, Australia. His work concentrates on the enhancement of thermal efficiency of passive solar design houses through the appropriate utilization of the thermal mass and insulation. He has created a number of new measures to characterize the thermal performance of housing using the dynamic approach. His research interest relates to structural engineering, energy efficiency of buildings, climate change, statistical and artificial intelligence methods.

Emeritus Professor Adrian Page received the Ph.D. degree in engineering from the University of Newcastle, Australia (UON) in 1979 and a BE in Civil Engineering from the University of New South Wales (UNSW) in 1965. Emeritus Professor Page is an internationally recognized researcher for his contribution to pure and applied research in the field of structural masonry and is the leader of the largest and most active masonry research group in Australia. His research interests include; masonry analysis, design and construction, material properties, analysis methods and constitutive models and sustainability. Page's research first gained international recognition for his fundamental work in the 1980s on the constitutive modelling of the in-plane behaviour of masonry.

Professor Behdad Moghtaderi received the Ph.D. degree in engineering from the University of Sydney after completing master of Engineering Studies from the University of Sydney. He is currently the Director of PRC for Frontier Energy Technologies \& Utilisation in the University of Newcastle, Australia. He served as the Honorary Secretary of The Australian and New Zealand Section of the Combustion Institute between 2007-2010. Within his area of expertise, Prof. Moghtaderi holds five patents attracting more than \$ 48 million in research funding in the past 12 years and with more than 300 publications, the world-renowned chemical engineer has helped solve some of the biggest issues in improving energy efficiency and developing low emissions coal and renewable energy technologies. 